\title{
Influence of individual heat pumps on wind power integration - Energy system investments and operation
}

\author{
Hedegaard, Karsten; Münster, Marie
}

Published in:

Energy Conversion and Management

Link to article, DOI:

10.1016/j.enconman.2013.08.015

Publication date:

2013

Document Version

Peer reviewed version

Link back to DTU Orbit

Citation (APA):

Hedegaard, K., \& Münster, M. (2013). Influence of individual heat pumps on wind power integration - Energy system investments and operation. Energy Conversion and Management, 75, 673-684.

https://doi.org/10.1016/j.enconman.2013.08.015

\section{General rights}

Copyright and moral rights for the publications made accessible in the public portal are retained by the authors and/or other copyright owners and it is a condition of accessing publications that users recognise and abide by the legal requirements associated with these rights.

- Users may download and print one copy of any publication from the public portal for the purpose of private study or research.

- You may not further distribute the material or use it for any profit-making activity or commercial gain

- You may freely distribute the URL identifying the publication in the public portal

If you believe that this document breaches copyright please contact us providing details, and we will remove access to the work immediately and investigate your claim 


\title{
Influence of individual heat pumps on wind power integration - Energy system investments and operation
}

Karsten Hedegaard $^{\text {a, * }}$, Marie Münster ${ }^{a}$

${ }^{a}$ Systems Analysis Division, DTU Management Engineering, Frederiksborgvej 399, P.O. Box 49, Build. 130, DK4000 Roskilde, Denmark.

*Corresponding author. Tel.: +45 4677 5158; fax: +45 4677 5199. E-mail addresses: khed@dtu.dk, karsten.hj@gmail.com Frederiksborgvej 399, P.O. Box 49, Build.130,DK-4000 Roskilde (K.Hedegaard).

\begin{abstract}
Individual heat pumps are expected to constitute a significant electricity demand in future energy systems. This demand becomes flexible if investing in complementing heat storage capabilities. In this study, we analyse how the heat pumps can influence the integration of wind power applying an energy system model that optimises both investments and operation, and covers various heat storage options. The Danish energy system by 2030 with around 50-60 \% wind power is used as a case study. Results show that the heat pumps, even without flexible operation, can contribute significantly to facilitating larger wind power investments and reducing system costs, fuel consumption, and $\mathrm{CO}_{2}$ emissions. Investments in heat storages can provide only moderate system benefits in these respects. The main benefit of the flexible heat pump operation is a reduced need for peak/reserve capacity, which is also crucial for the feasibility of the heat storages. Socio-economic feasibility is identified for control equipment enabling intelligent heat storage in the building structure and in existing hot water tanks. In contrast, investments in new heat accumulation tanks are not found competitive.
\end{abstract}


Key words: Residential heat pumps, Flexible electricity demand, Demand side management, Peak load shaving, Thermal building model, Optimisation.

\section{Introduction}

Wind power has great potential in mitigating $\mathrm{CO}_{2}$ emissions and improving security of supply through displacing use of fossil fuels in the energy system. The share of wind power is high in the Danish energy system, around 25-30 \% of annual electricity demand [1], and the Government plans to increase this share to $50 \%$ in 2020 [2]. This makes the Danish case interesting for

analysing challenges of integrating wind power that may be faced by other countries in the future.

Previous studies have shown that large heat pumps, electric boilers, and heat storages in combined heat and power (CHP) systems, as well as electric vehicles, can play a significant role in facilitating the integration of wind power [3-8]. Similarly, demand side management can contribute significantly to increasing system flexibility [9-13], and individual heat pumps in the residential sector could also contribute in this regard. Analyses show that individual heat pumps together with district heating form the best heat supply solutions in present and future energy systems [14, 15]. Furthermore, the use of individual heat pumps is expected to grow considerably in Denmark [16], thereby developing into a significant part of the total electricity demand. The electricity demand of the heat pumps becomes flexible if e.g. investing in control equipment, enabling intelligent heat storage in the building structure and/or in existing hot water tanks, and/or if investing in heat accumulation tanks for space heating. This can potentially provide system benefits in terms of e.g. rendering wind power investments more attractive and reducing the need for peak and reserve capacities. However, investments in heat storages in the 
households could suffer from low economies of scale and will in some aspects compete with other flexible energy technologies in the system. This makes it relevant to analyse individual heat pumps and supplementing heat storages in integration with the energy system, optimising both investments and operation.

Only few studies evaluate the effects that flexible operation of individual heat pumps can have on the system applying a large-scale energy system model. Papaefthymiou et al. [17] assess the system benefits of operating large scale installations of individual heat pump flexibly, using the building stock as thermal storage. Applying a case study of the German power system in 2030 with a renewable electricity share of 50-70 \% (hereof, two thirds wind power), it is found that flexible operation of the heat pumps can reduce system operation costs with 0.45-0.95 \% corresponding to 25-40 €/house/year [17]. Hedegaard et al. [18] compare the potentials of individual heat pumps and different heat storage options in terms of facilitating a fuel-efficient and cost-effective integration of wind power. In a case study of the Danish energy system in 2020 with $50 \%$ wind power, it is shown that the installation of heat pumps significantly reduces fuel consumption, while flexible operation provides only moderate fuel savings. Klobasa [19] analyses a broad range of demand response potentials and costs, including cooling and electric heating in the residential sector, and compares them to costs of conventional balancing technologies.

The above mentioned studies mainly focus on operational aspects without investigating how flexible heat pump operation can influence energy system investments. In reports by the Danish TSO and the Danish Energy Association $[20,21]$ it is estimated that flexible heat pump operation 
can significantly reduce investments in peak capacity and reduce system costs by 80-130 $€ /$ house/year on average (socio-economic costs) [22]. However, the applied model covers only operation of the system, while investments are estimated separately. Moreover, flexible operation is in not modelled but e.g. in [20] merely represented as a modified fixed demand profile, assuming that operation can be optimised within the day.

No existing studies have been identified, which analyse the system effects of individual heat pumps, applying a national scale energy system model that optimises both operation and investments. This is therefore the subject of this study. In a case study of the Danish energy system in 2030 with optimised wind power shares of around 50-60\%, we analyse how individual heat pumps and complementing heat storages affect investments in the energy system; particularly to which extent they can facilitate increased wind power investments and reduce the need for peak and reserve capacity. Moreover, we investigate to which extent investments in individual heat storages are socio-economically attractive. In this regard, we include competition with other flexibility measures in the system - here represented as large heat pumps, electric boilers, and heat storages in the CHP system. Effects on system costs, fuel consumption, and $\mathrm{CO}_{2}$ emissions are also quantified. The results are intended as input to policy makers in prioritising efforts and incentives within the field of individual heat pumps and wind power integration. The main research question investigated is: To which extent can individual heat pumps and complementing heat storages support an effective wind power integration?

We apply an add-on recently developed for the investment model Balmorel (see Section 2), which incorporates thermal building dynamics and various heat storage options for individual 
heat pumps. The model has been described in detail in [23]. Socio-economic cost minimisation is applied in order to identify what is optimal for the system as a whole. The article is structure in the following way; Section 2 describes the Balmorel model and the add-on developed. Section 3 presents how the model has been applied, covering scenarios and input data. In Section 4, results of the energy system analysis are presented, and a discussion and conclusion is given in Section 5 and 6. Finally, Section 7 outlines suggestions for future work.

\section{Model: Balmorel with thermal building model add-on}

Balmorel is a partial equilibrium model assuming perfect competition [3, 24]. The Balmorel model has in previous studies been used for analysing e.g. wind power development, security of supply, the role of district heating, development of international electricity markets, the role of demand response, compressed air energy storage, unit commitment, international markets for green certificates and emission trading as well as evaluation of environmental policies cf. e.g. $[15,25]$.

The model minimises total costs of the system, covering annualised investment costs, operation and maintenance costs of existing and new units, and fuel and $\mathrm{CO}_{2}$ quota costs. In this process, the model optimises investments in power/heat production, storage, and transmission capacities, and the operation of the system. The optimisation is done subject to a number of constraints including satisfaction of demands for electricity and heat in each time period, renewable energy potentials, and technical restrictions on units in the system. The model is deterministic assuming perfect foresight and the linear version applied does not include start-up costs, minimum load requirements, or part load efficiencies [3, 24]. 
The model operates with three geographical entities, namely countries, regions, and areas. Countries are divided into regions connected with transmission lines, while regions are further divided into areas. Electricity supply and demand is balanced on regional level, and heating is balanced on area level. In this study, the existing model structure in Balmorel is used for handling the integrated power and district heating system. Individually heated one-family houses are represented using the new thermal building model add-on. In Balmorel, the optimisation is performed with a yearly time horizon, where the year is divided into seasons, which are further divided into time periods. When applying an hourly time resolution, seasons represent weeks, while time periods represent hours. A full description of the Balmorel model can be found in [24, 26].

Heat pumps (compression heat pumps) are in Balmorel represented as commonly in energy system models, where the relation between heat output $\left(\mathrm{Q}_{\mathrm{t}}\right)$ and electricity input in a given time period $\left(\mathrm{P}_{t}\right)$ is expressed as $\mathrm{Q}_{\mathrm{t}}=\mathrm{COP} \cdot \mathrm{P}_{\mathrm{t}}$, where COP is the average annual coefficient of performance for the heat pump. In the thermal building model add-on, the individual heat pumps (ground source heat pumps and air/water heat pumps) are supplemented by an electric boiler to cover peak loads in order to reduce heat pump investment costs, as in reality. The capacity shares of heat pump and electric boiler, respectively, are defined in the input data. When the heat pumps are connected to heat storage, they can be operated flexibly. The large heat pumps are in Balmorel connected to the district heating storages, while the individual heat pumps can utilise the different heat storage options covered in the thermal building model add-on, if the required investments are made. 
The thermal building model applied represents houses with radiator heating as well as houses with floor heating, as the central heating system. In the model, houses with radiator heating can utilise the option of storing heat passively in the building structure through radiation, thermal conductance, and convection. The term passively refers to the fact that heat is stored without the use of a heat transferring media going in and out of the storage. The storage concept mainly utilises the heat capacity of internal constructions in walls, ceiling, and floor, while windows, doors, and furniture have minor influence [18]. Houses with (concrete) floor heating can via the water tubes in the floor foremost store heat actively in the large thermal mass of the concrete floor $^{1}$. Thermal storage tanks for space heating and hot water are also covered, representing other options of enabling flexible heat pump operation. The model is a linear state-space model and is based on physical definitions and relations of heat transfers and heat capacities. A full description of the model is given in [23].

\section{Application}

\subsection{Scenarios}

Three main scenarios are compared in the analysis: NOiHP, iHP, and iHP-Flex (see Table 1). By comparing the scenarios NOiHP and iHP, it is analysed how the installation of individual heat pumps affect the energy system, when not operated flexibly. The difference between the scenarios iHP and iHP-Flex reveal the effect of investing in heat storages complementing the heat pumps, thereby facilitating flexible operation. Investment in heat storages will only occur to the extent that it is socio-economically attractive, in the optimisation. Focusing on the largest storage potentials, the following heat storage options are optimised in the main scenarios:

\footnotetext{
${ }^{1}$ In addition, heat can be stored passively in the rest of the building structure [65].
} 
- Intelligent heat storage in the building structure: investment in digital thermostats ${ }^{2}$, enabling intelligent control of the central heating system, and in a central controller communication with the power system [18, 27]. For houses with radiator heating, this renders it possible to utilise passive heat storage in the building structure, while for houses with (concrete) floor heating, it foremost facilitates using active heat storage in the concrete floor.

- Heat accumulation tanks: investment in a heat accumulation tank for the space heating circuit of a size up to 1000 litres per house and in a central controller communicating with the power system [18].

A small hot water tank of around 180 litres [28] is typically installed in connection with individual heat pump installations. The hot water tank can to some extent also support flexible heat pump operation if investing in control equipment (a central controller). The feasibility of investing in this option is analysed in a supplementary analysis (see Section 4.4). In a sensitivity analysis, the feasibility of the space heating storages listed above is moreover investigated in a situation where the investment in intelligent use of the hot water tank has already been made (see Section 4.4). This analysis approach is applied in order to avoid double counting the cost of the common control equipment (the central controller) and to ensure a reasonable computation time.

The system model covers the power \& district heating sectors in not only Denmark, but also Norway, Sweden, Finland, and Germany, in order to cover the influence of electricity import/export. For Denmark, individually heated one-family houses are additionally modelled,

\footnotetext{
${ }^{2}$ On each radiator for radiator heating and in each room for floor heating.
} 
representing the bulk, 78 \% [29], of individual heating. Existing individual heating installations are assumed decommissioned by 2030 based on a typical lifetime of around 15-20 years [14, 30].

Denmark is divided into a Western power region, being synchronous with the former UCTE power system, and an Eastern power region being synchronous with the former Nordel power system (both power systems are today represented by ENTSO-E). In order to limit computation time, the Danish district heating system is aggregated into 4 areas. This aggregation has no real influence on the results since 1) A linear model is applied, i.e. investments can be made in continuous capacity sizes. 2) The total district heating demand for each actual heating area covers several thousands of consumers and is thus already very smoothened from aggregation. 3) The district heating expansion is in the analysis fixed based on [31]. 4) A large share of existing district heat generation capacities are decommissioned towards 2030. Due to the focus on individual heating, 20 different individual heating areas with different characteristics are modelled (see Section 3.4).

\subsection{Period simulated}

Based on a need to limit computation time, five weeks are simulated to represent a full year, hereof four weeks in the heating season and one summer week. In order to ensure good representation of variations in wind power, electricity, and heat demands, an hourly time resolution within each week is applied. When scaling up to a full year, weighting factors are applied to account for the period length that each of the simulated weeks represent. The weeks have been carefully selected based on the following criteria:

a) The weeks give a good representation of the varying heat demands over the seasons. 
b) The highest net load (electricity demand minus wind power) over the year for Denmark is covered. This captures the need for peak capacity for periods, where electricity demand is high and wind power low.

c) The highest total load (conventional plus flexible electricity demand) over the year for Denmark is covered. This captures the need for adequate production and reserve capacity, via a capacity balance restriction applied.

d) Peaks in individual heat demand over the year are covered. This ensures good representation of the electric boiler, which supplements the heat pump in covering peak loads [32]. Due to its low efficiency (around 1 compared to an applied COP of 3.1-3.8 for the heat pump), the electric boiler is highly influential on peaks in electricity consumption for the total heat pump unit.

e) The weeks cover significant wind power variations.

The heat transfer coefficients for the houses have been calibrated to give the annual space heating demand for each building category (cf. Table 3). The calibrated heat transfer coefficients deviate less than $2 \%$ from values corresponding to a full year simulation. This shows that the simulated weeks give a very good approximation of the space heating demand over a full year. Based on this and the selection criteria a-e, the modelled period is thus representative for a full year.

\subsection{Energy demands applied}

Electricity and heat demands in 2030 are based on the Future scenario set up by The Danish Commission on Climate Change Policy [31] (see Table 2). In this scenario, the district heating share for heating of buildings is increased from $46 \%$ in 2008 to $55 \%$ in 2030 [33]. 
The stock of existing individually heated one-family houses in Denmark (app. 716,000 houses) is modelled, representing the large majority (94\%) of the individually heated one-family houses by 2030.

\subsection{Modelling of individually heated one-family houses}

The development in the Danish building stock and in the heat demands towards 2030 is based on the Future scenario in [31]. As a result, the heat demand for existing individually heated onefamily houses is assumed reduced by about $25 \%$ towards 2030, mainly due to heat savings and secondarily due to demolition of old buildings. The houses are divided into 3 different categories, depending on the year of construction; reflecting changes in insulation standards (see Table 3). The assumed heat savings have been distributed on the different construction periods based on heat saving potentials given in [34].

Radiator systems have for a long period of time been the typical type of central heating system installed in connection with construction of new houses in Denmark. Use of floor heating as central heating system (i.e. not only in the bathroom) was introduced during the 1990s and has from around 1995-2000 been the common type of central heating system installed in new houses [38, 39]. Against this background, houses constructed from 1995 are assumed to have a central floor heating system and houses constructed before 1995, a radiator-based central heating system. This results in radiator heating covering $95 \%$ of the individual heat demand of existing one-family houses in 2030. Installation of floor heating as central heating system in existing buildings is much more expensive than when installed in the construction phase [40]. Therefore, 
installation of floor heating in existing houses is typically only carried out in connection with full renovation of the floor [18]. Floor renovations are expensive, as also reflected by the fact that this is not included among the feasible heat saving measures in [31]. Installation of floor heating in existing houses has therefore been neglected.

Houses with a radiator-based central heating system have been divided into three groups depending on the heat capacity of the building structure that can be utilised for passive heat storage diurnally. This heat capacity is based on typical values for Danish buildings as given in [41] and on the following general distribution: $60 \mathrm{Wh} /{ }^{\circ} \mathrm{C} / \mathrm{m}^{2}$ floor area: $25 \%$ of the houses, 100 Wh $/{ }^{\circ} \mathrm{C} / \mathrm{m}^{2}$ floor area: $50 \%$ of the houses, and $140 \mathrm{Wh} /{ }^{\circ} \mathrm{C} / \mathrm{m}^{2}$ floor area: $25 \%$ of the houses [42]. Overall, the stock of individually heated one-family houses is represented as 10 different heating areas in Eastern and Western Denmark, respectively. The 10 areas in each region constitute 1 floor heated area and 9 areas with radiator heating, expressing combinations of insulation standards and heat capacities of the building structure. Concrete floor heating systems have been applied as this is the dominant type of water-based floor heating system installed in houses in Denmark, due to its low costs [39, 43]. A typical concrete layer of $10 \mathrm{~cm}$ has been assumed (67 $\mathrm{Wh} /{ }^{\circ} \mathrm{C} / \mathrm{m}^{2}$ floor area) $[39,43]$.

Reflecting the average diurnal indoor temperature profile for 28 Danish households with heat pump installations [44], a constant indoor temperature requirement of $21.5^{\circ} \mathrm{C}$ is applied in the iHP scenario. [45] confirms that a constant indoor temperature setting is typical for current heat pump installations in one-family houses. This setting has moreover been found to give the best correlation with diurnal space heating profiles for the measured houses. Based on typical 
variations in indoor temperatures for the households [44] (measured in living room/kitchen), an interval of $20-23^{\circ} \mathrm{C}$ is allowed in the iHP-Flex scenario during the day. The allowed temperature interval at night is set to $19-22{ }^{\circ} \mathrm{C}$ based on $[46,47]$. Allowing the indoor temperature to vary within such moderate intervals facilitates utilising the heat storage capacity of the building structure for flexible heat pump operation. Typical diurnal and seasonal variations in ambient air temperatures are represented using hourly data for the Danish design reference year [48].

Individual heat pumps can mainly be operated flexibly within the day, given the heat storage options presented [49]. In comparison, large heat pumps can be connected to the larger district heating storages, which give a higher level of flexibility. As such, large heat pumps can be activated flexibly in periods of up to several days, e.g. responding to longer periods with high wind power and low electricity prices. Furthermore, the large heat pumps can be supplemented by a fuel based unit (CHP unit or a fuel boiler). This means that large heat pumps can be turned off in longer periods when wind power is low and electricity prices are high [49].

\subsection{Fuel and $\mathrm{CO}_{2}$ prices}

The fuel and $\mathrm{CO}_{2}$ prices used in the main scenarios are based on [31], which is based on IEAs Reference scenario [50] (see Table 4). In a sensitivity analysis, fuel and $\mathrm{CO}_{2}$ prices corresponding to a very ambitious international climate mitigation are applied [31, 50]. Fossil fuel prices in this scenario are lower, mainly due to lower demand resulting from $\mathrm{CO}_{2}$ reduction requirements, while $\mathrm{CO}_{2}$ prices are significantly higher. 


\subsection{Energy policies implemented in model}

The following Danish energy policies towards 2030 have been implemented in the model:

- Wind power must in Denmark by 2020 correspond to at least $50 \%$ of the national electricity consumption [2].

- The use of coal at Danish heat and power plants is phased out by 2030 [2]

- Individual oil boilers are phased out by 2030.

- 1.2 Mtonnes straw and 0.2 Mtonnes wood chips must be incinerated at Danish heat and power plants annually [52].

The Danish energy policy also includes a target of electricity and heat generation to be $100 \%$ based on renewable energy by 2035 [53]. The policy does not specify whether this applies to district heating only or all heating including individual heating. In the light of this uncertainty, it is chosen to include the possibility to invest in individual natural gas boilers in the model by 2030. Historically, the Danish natural gas grid expansion for supplying heat to one-family houses has declined since 1999 [29]. The use of individual natural boilers is therefore constrained to the amount supported by the current natural gas grid, and further reduced due to the heat savings assumed towards 2030. This corresponds to allowing new natural gas boilers only in the form of reinvestments.

Binding EU energy targets apply for the member states in 2020, ensuring a renewable energy share of $20 \%$ for EU as a whole for the gross final energy consumption for electricity, heating, cooling, and transport [54]. Each of the EU member states have set up national renewable energy action plans that will ensure compliance with these targets. Planned renewable energy capacities, 
as given in these plans, have been implemented in the model for the other EU countries modelled (Germany, Sweden, and Finland). Where relevant, planned renewable electricity generation levels have furthermore been implemented as minimum generation levels. Other energy policies implemented in the model include planned nuclear and hydro power capacities and the German policy of phasing out nuclear power towards 2022 [55].

The Danish energy policy, targeting a 100 \% renewable heat and power sector by 2035, is more ambitious than the actions needed in the other countries to comply with EUs renewable energy targets for 2020. Particularly the phasing out of the coal in Denmark by 2030 could lead to significant net import of electricity from other countries. A large permanent net import of electricity cannot be considered realistic or reasonable from a security of supply perspective, as neighbouring countries will face similar challenges of converting their energy systems towards sustainability [31]. Therefore, as done in [31], Danish electricity generation is constrained to be minimum equal to the electricity demand on annual level.

\subsection{Biomass \& waste potentials}

Use of straw, wood chips/waste, firewood, biogas, and municipal waste is in the analysis limited to the national resources. Wood pellets import is allowed since wood pellets are to a large extent traded internationally. The Danish biomass and waste potentials applied are presented in Table 5.

\subsection{Investment options modelled}

In the optimisation, it is in all five modelled countries made possible to invest in the technologies presented in Table 6, for satisfying the electricity and district heating demand. Investments in 
open cycle gas turbines and natural gas boilers are allowed also in the Danish system, since these are suited in scale and technology for a later shift to using renewable fuels (biogas or gasified biomass) [31]. Based on [56], investment costs are in the model annualised with a discount rate of $3 \%$ given in fixed prices. All costs in the study are socio-economic and are given in €-2011.

In individually heated areas, the model includes possibilities to invest in the technologies presented in Table 7. Individual heat pumps are in the analysis dimensioned to $77 \%$ of the total heat output capacity, reflecting the typical situation in Danish heat pump installations (72\%-82 \% [32]). Thereby, the heat pumps cover around $99 \%$ of the annual heat demand, while the supplemental electric boilers cover the rest.

Planned expansions of electrical transmission capacities towards 2030 have been included. The possibility to invest in further transmission capacities has however been excluded in the main scenarios. This is most reasonable considering that most of the Northern European countries other than Denmark are here modelled without representation of internal bottlenecks in the power system. Nevertheless, the influence of allowing further transmission capacity investments is covered in a sensitivity analysis.

\section{Results}

When not allowing investments in individual heat pumps (NOiHP scenario), the investments in individual heating installations constitute natural gas boilers, to the extent supported by the natural gas grid (37 \% of total individual heat demand), and then wood pellet boilers to cover the rest of the heat demand. When investment in individual heat pumps are allowed (iHP and iHP- 
Flex scenario), air-water heat pumps are installed in all individual heating areas. This represents a significant electricity demand of 4.3 TWh.

In the iHP scenario, the heat pumps are restricted to cover the net heat demand in each hour, i.e. heat transmission and ventilation losses minus heat contributions. As shown in Fig. 1, space heating will in this situation (non-flexible operation) be highest, when ambient temperatures are lowest.

When allowing investments in heat storages for the heat pumps (iHP-Flex scenario), investment in intelligent heat storage in the building structure is observed in $34 \%$ of the houses. The heat storage investments occur within all 20 defined categories of individually heated houses; however the investments are highest in buildings with high heat capacities (typically corresponding buildings with a high share of concrete). No investments in heat accumulation tanks are observed, due to their higher investment costs. As shown in Fig. 1, the heat storage capability of the buildings renders it possible to prioritise the operation of the heat pumps for hours with low electricity prices. The electricity prices in the model represent the marginal electricity generation cost in the given power region and time period. Fig. 1 thus illustrates that when connected to heat storage, the heat pump operation is optimised in integration with the energy system.

The interaction between heat pumps and heat storages in each individually heated area is modelled on aggregated level. This means that a given heat storage capacity can be utilised among all heat pumps within the area. This is evident from Fig. 1, where the heat storage 
investments occurring in $34 \%$ of the houses render it possible to operate a larger share of the heat pumps flexibly to some extent, e.g. reflected by the significant load reductions in hour T109 and T163. As such, the model implies best case conditions for the heat storages, since the flexibility can be distributed among the houses in this way. Ideally, each of the many thousands of individually heated houses should be modelled separately (716,000 in this case); however it would hardly be possible to run such a model.

\subsection{Energy system investments}

In all three scenarios for 2030, the bulk of the annual Danish electricity generation is based on wind power (57-61 \%) and wood chips (28-31\%), while straw (4\%), municipal waste (6-7 \%), wood pellets (1\%), and natural gas (1\%) contribute with smaller shares. The diminishing share of fossil-based electricity generation is mainly explained by the implemented political goal of phasing out coal at Danish power plants.

The investments in new electricity and heat generation capacities in Denmark for the three different scenarios are illustrated in Fig. 2. As shown, the new electricity generation capacities cover onshore and offshore wind power, biomass CHP steam turbines, and open cycle gas turbines. The wood chip and straw CHP plants are mainly used for intermediate load operation, supplementing the large amounts of wind power. Open cycle gas turbines are used as peak/reserve capacities (cf. Fig. 3).

Fig. 2a shows that the installation of individual heat pumps facilitates increased investments in wind power, wood chip CHP, and open cycle gas turbines (iHP vs. NOiHP scenario). The 
increase in wind power capacities occurs in order to meet the increase in electricity demand from the installation of the heat pumps. As such, wind power covers $97 \%$ of the increase in annual electricity demand, while natural gas peak power plants cover the rest. Part of the explanation for this is that the competitor coal is politically phased out by 2030 in the Danish system and that the other low cost fuels, wood chips and municipal waste, are constrained by the available national resources. This leaves good conditions for wind power. Moreover, the electricity consumption of the heat pumps is distributed over many hours in the day, even without flexible operation (see Fig. 1) and both heat demand and wind power is typically high in cold periods. This creates good possibilities for utilising wind power in covering the electricity demand for the heat pumps while using dispatchable power capacities to back it up. In contrast, e.g. dumb charging of electric vehicles would typically be concentrated in a few hours of the day when people return from work, making wind power utilisation difficult in this case.

The increased investments in wood chip CHP and open cycle gas turbines are driven by a need to supplement the fluctuating wind power. In this regard, these dispatchable technologies also cover an increased need for peak/reserve capacities imposed by the heat pumps. The annual wood chips-based electricity generation is however identical in all scenarios since the wood chips consumption is limited by the national biomass resources.

As shown in Fig. 2a, the investments in open cycle gas turbine and wood chip CHP capacities are reduced when the heat pumps are operated flexibly (440 MW, iHP-Flex scenario compared to iHP scenario). The reason is the heat pumps contribute in peak load shaving, when operated flexibly, which reduces the need for peak/reserve capacity. The flexible heat pump operation 
moreover facilitates reduced wind power investments onshore and increased investments offshore. This is due to the fact that flexibility added to a system generally improves the conditions for technologies with relatively high investment costs and low variable costs. In this regard, offshore wind power has higher investment costs, but on the other hand higher obtainable full load hours (and a different variation profile) compared to onshore wind power.

The investments in large heat pumps in the district heating system are clearly reduced with the installation of individual heat pumps (see Fig. 2b). This is explained by the increase in electricity demand resulting in generally increased electricity prices, making large heat pumps less attractive. The lower investment in large heat pumps is the explanation for the increase in solar thermal in the iHP scenario.

When adding flexibility to the individual heat pumps (iHP-Flex scenario), the investment in large heat pumps is reduced further. The reason is that the individual heat pumps compete with the large heat pumps in placing operation in low electricity price periods. The reduced investments in large heat pumps result in increased investments in natural gas heat only boilers or solar thermal and in thermal storages in the district heating system. It can be noted that the solar thermal capacities are relatively large due to their low number of full load hours (app. 730).

\subsection{Fuel consumption and $\mathrm{CO}_{2}$ emissions}

The primary energy consumption of the Danish heat and power system in the three scenarios is shown in Fig. 4. It can be seen that the installation of individual heat pumps facilitates a significant increase in wind power generation (iHP vs. NOiHP scenario). This is due to the 
increased wind power investments presented in Section 4.1. The consumption of wood chips and municipal wastes is the same in all scenarios due to the resource constraints. The use of straw for heat \& power generation only occurs to the extent enforced by the Danish biomass agreement and is therefore unchanged across scenarios. The individual heat pumps displace a significant amount of wood pellets and natural gas used in individual boilers. This reduces the pressure on biomass resources and also increases national security of supply in this case since wood pellets are in Denmark typically imported.

Flexible operation of the individual heat pumps merely results in a slight increase in wind power generation and a slight decrease in natural gas consumption, due to an avoided use of open cycle gas turbines for peak load operation (iHP-Flex vs. iHP scenario).

The total fuel consumption excl. wind is reduced significantly as a result of the individual heat pump installations ( $23 \%$ ). This is explained by the higher efficiency of the heat pumps, and that the increase in electricity demand imposed by the heat pumps is largely met by wind power. When activating flexible operation of the heat pumps, an additional minor reduction is achieved (0.3 \%). The $\mathrm{CO}_{2}$ emissions in 2030 are reduced considerably with the installation of individual heat pumps (37 \%) (iHP scenario) and further reduced by only $2 \%$ with flexible operation of the heat pumps (iHP-Flex scenario). It can be noted that the percentagewise $\mathrm{CO}_{2}$ reductions are enlarged by the Danish no coal policy, which yields generally low absolute $\mathrm{CO}_{2}$ emissions. 


\subsection{System costs}

The annualised socio-economic system costs for the three scenarios are presented in Fig. 5. As shown, fuel costs are reduced considerably with the installation of individual heat pumps. This is explained by the high efficiency of the individual heat pumps, and that the increase in electricity demand is largely covered by wind generation. Furthermore, the displaced technologies, natural gas boilers and wood pellet boilers, have relatively high fuel costs. Investment costs and fixed O\&M costs are on the other hand increased, due to the larger investment costs (annualised) of individual heat pumps compared to individual gas boilers, and the increased investments in wind power and dispatchable power capacities needed along with the heat pump installations. In total, system costs for the Danish heat and power system are reduced significantly with the installation of individual heat pumps (12\%). The cost reduction achieved when operating the heat pumps flexibly is moderate (0.9\%).

The flexible operation of the heat pumps provides a socio-economic cost reduction of around 120 $€$ per year per house investing in intelligent heat storage in the building structure. This cost reduction is mainly caused by savings on energy system investments (incl. fixed O\&M, mainly peak/reserve capacities), as illustrated in Fig. 6.

Due to the self sufficiency constraint implemented, electricity import equals export on annual level. However, significant electricity trade is utilised hour-by-hour as expected.

For the other countries modelled, energy system investment and operation is practically unchanged by the installation of individual heat pumps and heat storages in Denmark. 
Overall, the results indicate that individual heat pumps can contribute significantly to facilitating larger wind power investments and reducing fuel consumption, $\mathrm{CO}_{2}$ emissions, and system costs. Heat storages for the heat pumps, enabling flexible operation, have shown to provide only moderate system benefits in these respects. Investment in intelligent heat storage in the building structure is identified as socio-economically feasible in a given share of the houses, while heat accumulation tanks are not identified as socio-economically competitive.

\subsection{Sensitivity analyses}

The general results stated above have been confirmed in all sensitivity analyses presented in this section. However, the share of houses in which intelligent heat storage in the building structure is feasible, the achieved reduction in peak/reserve capacity, and the average system benefit per house, is found sensitive to certain factors. These sensitivities are presented in the following, focusing on the most important deviations from the main scenario. Other exploratory sensitivity analyses are also presented.

As a first test, investment in intelligent heat storage in the building structure is forced through in all houses with heat pump installations, instead of optimising the heat storage investments as in the main scenario. This provides practically the same reduction in peak/reserve capacity, while the average system benefit per house with flexible heat pump operation decreases substantially (to $8 € /$ house/yr compared to $120 € /$ house/yr in the main scenario). This illustrates that the optimised heat storage investments in the main scenario have largely been made to the extent that peak/reserve capacities can be cost-effectively reduced. 
If forcing through investments in both 1000 litres heat accumulation tanks and in the enabling of intelligent heat storage in the building structure in all houses, only moderate increases in wind power generation ( $0.1 \mathrm{TWh})$ and reductions in fuel consumption ( $0.5 \%)$ are still observed; while system costs are increased moderately (1\%). Peak/reserve capacity investments are reduced only slightly more than when optimising the heat storage investments (460 MW compared to 440 MW).

When assuming a heat pump capacity share in the low end, $72 \%$, the impact of the electric boiler in peak load hours becomes more critical in the situation without flexible operation. As a result, a larger reduction in peak/reserve capacity is achieved when operating the heat pumps flexibly (560 MW, with optimised heat storage investments). Correspondingly, if assuming a heat pump capacity share in the high end, $82 \%$, a lower reduction in peak/reserve capacity is achieved (290 MW). When assuming higher investment costs and COP (3.7-4.0) for the heat pumps as given in [30], the heat pumps still outcompete all other individual heating installations. However, the higher COP results in lower impact on peak/reserve capacities, which are therefore reduced by only 320 MW with the flexible heat pump operation.

If assuming $50 \%$ higher/lower investment cost for control equipment (digital thermostats and central controller), investment in intelligent heat storage in the building structure occurs in $19 \%$ and $75 \%$ of the houses, respectively. Peak/reserve capacities are reduced by 426-430 MW and the average system benefit per house is $190 € /$ house/yr and $60 € /$ house/yr, respectively. If allowing an indoor temperature of $20-23^{\circ} \mathrm{C}$ at night, only moderate changes are observed since the peak loads occur in the day time. When applying a discount rate of $5 \%$, generally lower 
wind penetration and higher investments in thermal power plants is observed. The reduction in peak/reserve capacity obtained with flexible heat pump operation is higher (640 MW).

When assuming an ambitious international climate mitigation (high $\mathrm{CO}_{2}$ prices, lower fossil fuel prices, cf. Table 4), the reduced investment in peak/reserve capacity mainly comprises wood pellet CHP, and the system benefit is increased to $180 €$ /house/yr. If assuming $50 \%$ higher biomass prices, wind power investments are increased significantly, wood-based CHP investments reduced considerably, and open cycle gas turbine investments increased considerably. However, the overall outcome of the analysis is not changed. If not restricting balance in electricity import and export on annual level, the net electricity import on annual level is increased from 0 TWh to 2-3 TWh without altering the overall outcome of the analysis. The overall picture is not changed either, if allowing investment in transmission capacities further than planned.

In another sensitivity analysis, we have assumed intelligent utilisation of the existing hot water tanks (180 litres [28]) by forcing through investment in a central controller in all houses. This leads to a reduction of the required investments in peak/reserve capacity by about $310 \mathrm{MW}$. In this situation, the possibility for achieving further reductions in peak/reserve capacity, by investing in intelligent heat storage in the building structure, is limited to $120 \mathrm{MW}$. However, since investment in the central controller in this case has already been made, the additional investment cost of enabling intelligent heat storage in the building structure is reduced (to cover only the digital thermostats). As a result, investment in further flexibility still occurs in a significant share of the houses (48\%). When optimising the investments in the intelligent use of 
existing hot water tanks, investments occur in about 20-70 \% of the houses, depending on the cost of the controller (applying $\pm 50 \%$ of the cost given in Table 7 ).

\section{Discussion}

The results confirm the findings of previous studies $[14,15]$ in identifying individual heat pumps as highly socio-economically competitive in non-district heating areas. Our results indicate that in terms of making wind power investments more attractive and reducing system costs, fuel consumption, and $\mathrm{CO}_{2}$ emissions, the installation of the heat pumps is the most important step, while the system benefits of adding flexibility to the heat pumps are moderate. This is in line with the findings in [18], which identified a similar pattern concerning effects of heat pumps and heat storages on fuel consumption of the system. We find that utilising the heat storage capacity of the building is socio-economically feasible, while heat accumulation tanks are not competitive. This is also in line with the findings in [18].

The possibility for reducing investment in peak/reserve capacity is identified as crucial for the feasibility of heat storages for the heat pumps. This is illustrated by the fact that savings on energy system investment generally constitute the largest part of the cost reduction achieved with flexible heat pump operation. The substantial decrease in the system benefit per house, with an increasing number of flexible heat pump installations, is another illustration of this. This result is in agreement with patterns previously identified for the case of EVs in [3], which found that system benefits per smart vehicle decrease substantially with an increasing number of EVs. 
The achievable reduction in peak/reserve capacity identified, 300-600 MW, is on level with the identified peak load shaving potential in [64] for smart charging of EVs in the Finnish system (540 MW). Furthermore, the identified system costs reduction, due to flexible operation of the heat pumps, generally around $0.6-1.1 \%$, is on level with the system cost reduction of $0.45-0.80$ $\%$ found in [17]. If forcing through investment in intelligent heat storage in the building structure and in 1000 litres heat accumulation tanks in all houses with heat pump installations, and excluding investment costs for the storages, the system benefits become comparable to the results in [20, 21] and [17]. For this case, a system benefit of about $50 € /$ house/year is identified, i.e. close to the result in [17] (25-40 €/house/year) and significantly lower than the estimate in [20, 21] (80-130 €/house/year).

As the applied model is deterministic and does not include start-up costs, minimum load requirements, or part load efficiencies, the potentials for reducing operation costs through flexible heat pump operation are conservatively represented. However, we include effects on investments, in contrast to previous studies modelling and analysing the impacts of individual heat pumps and supplementing heat storages on the energy system. Our use of an aggregated energy system model means that heat storages are represented optimistically in the sense that the flexibility provided by an optimised heat storage capacity can be distributed among the heat pumps within the given area. Even under these conditions, only moderate system benefits have been identified for the heat storages. 


\section{Conclusion}

The influence of individual heat pumps on wind power integration has been analysed using a model that optimises both investments and operation of the energy system. The Danish energy system by 2030 with around 50-60 \% wind power is used as case. The optimisations result in a large scale installation of heat pumps in individually heated one-family houses (716,000 houses, 4.3 TWh-e).

We find that individual heat pumps can contribute significantly in facilitating larger wind power investments and in reducing system costs, fuel consumption, and $\mathrm{CO}_{2}$ emissions. In addition, the heat pumps can reduce the pressure on the limited biomass resources, due to displacement of individual wood pellet boilers. The system benefits of the heat pumps are first explained by their high efficiency and socio-economic competitiveness. Moreover, the aggregated electricity demand profile of the heat pumps is well suited for integrating wind power, even without flexible operation of the heat pumps. As a result, the increase in electricity demand imposed by the heat pumps can largely be covered by increased wind generation, while supplementing with dispatchable power generation. In the case analysed, the political phase out of coal in Denmark by 2030 and the constrained biomass resource availability creates particularly good conditions for wind power.

When investing in individual heat storages, the heat pumps contribute in peak load shaving, and their operation is prioritised for hours with low electricity prices. However, the flexible operation provides only moderate system benefits. Hereof, the main benefit is a reduced need for peak/reserve capacity investments of about 300-600 MW for the case analysed, corresponding to 
the size of a large power plant. The possibility for reducing peak/reserve capacity investments is identified as crucial for the feasibility of the heat storages.

It is found that investments in intelligent heat storage in the building structure can be feasible to some extent, i.e. in around $20-75 \%$ of the houses with heat pump installations, depending on the cost of control equipment in particular. The flexible operation of the heat pumps provides a socio-economic cost reduction of about 60-200 € per year per house investing in this storage option. The result intervals have been identified through various sensitivity analyses covering e.g. variation in investment cost of control equipment, COP, investment costs, and capacity share of the heat pumps, discount rate, as well as fuel and $\mathrm{CO}_{2}$ prices. A reduction in the peak/reserve capacity requirement can also be obtained if investing in control equipment that enables intelligent use of the hot water tank typically installed in combination with heat pumps. Investment in this option is found feasible in around $20-70 \%$ of the houses. In contrast, investments in heat accumulation tanks are not found competitive due to their larger investment costs.

The main benefit of the flexible heat pump operation, namely the reduced peak/reserve capacity requirement, will not be visible on the electricity bills paid by the individual heat pump owners. Some of this benefit should therefore be transferred to the heat pump owners when developing incentives for them to invest in heat storage capability. The relevance of this is reflected by the fact that under current regulation it is, according to the Danish TSO, not attractive for heat pump owners to invest in flexible operation, even if gaining access to both the spot market and the regulating power market [22]. 
Overall, large-scale installation of individual heat pumps is identified as an important step in supporting the integration of wind power. Heat storages, facilitating flexible operation of the heat pumps, can contribute only moderately in this regard. When policy makers prioritise efforts and public funds for creating incentives within this field, first priority should thus be given to ensure a large-scale deployment of the heat pumps. The enabling of flexible operation should be given second priority.

\section{Future work}

After having assessed the socio-economically feasibility of investments in individual heat pumps and heat storage options, the next relevant step would be to analyse the feasibility of the technologies seen from a private economic perspective. Whether individual heat pumps and supplemental control equipment and heat storages will in fact be installed, depends heavily on the regulation and incentives. It would therefore be interesting to analyse to which extent the existing regulation and incentives promote the socio-economically optimal solutions and whether further incentives are needed. Furthermore, it would be relevant to analyse how flexible operation of the heat pumps affect investments in distribution grid enhancements. Supplementary

analyses, where investments in individual natural gas boilers are excluded, could also be relevant in the light of the long term goal of moving towards a renewable energy society. Finally, it would be interesting to include additional competing flexible demand technologies, such as electric vehicles, in analysing the impacts on wind power integration. 


\section{Acknowledgments}

The authors would like to thank Bernd Müller and Erika Zvingilate for providing heat demand data for the Danish building stock from the heat atlas. Thanks are also given to Kenneth Karlsson and Olexandr Balyk for discussing preconditions for the analysis and to the reviewers for constructive comments on the article.

\section{References}

[1] Danish Energy Agency. Energy statistics 2011. < $\underline{\text { http://www.ens.dk/da- }}$ dk/info/talogkort/statistik_og_noegletal/aarsstatistik/Sider/Forside.aspx >; 2012 [accessed 05.01.13] [in Danish].

[2] Danish Ministry of Climate, Energy and Buildings. The Governments' energy and climate political goals and the results of the energy agreement in 2020.

<http://www.kemin.dk/Documents/Presse/2012/Energiaftale/Faktaark\%202\%20energi\%20og\%2 0klimapolitiske\%20mal.pdf >; 2012 [accessed 08.12.12] [in Danish].

[3] Kiviluoma J, Meibom P. Influence of wind power, plug-in electric vehicles, and heat storages on power system investments. Energy 2010;35(3): 1244-55.

[4] Hedegaard K, Ravn H, Juul N, Meibom P. Effects of electric vehicles on power systems in Northern Europe. Energy 2012;48(12):356-68.

[5] Mathiesen BV, Lund H. Comparative analyses of seven technologies to facilitate the integration of fluctuating renewable energy sources. IET Renewable Power Generation 2009;3:190-204.

[6] Ekman CK, Jensen SH. Prospects for large scale electricity storage in Denmark. Energy Convers Manage 2010;51(6):1140-47. 
[7] Østergaard PA. Wind power integration in Aalborg Municipality using compression heat pumps and geothermal absorption heat pumps. Energy 2013;49:502-8.

[8] Blarke MB. Towards an intermittency-friendly energy system: Comparing electric boilers and heat pumps in distributed cogeneration. Appl. Energy 2012;91(3):349-65.

[9] Zehir MA, Bagriyanik M. Demand Side Management by controlling refrigerators and its effects on consumers. Energy Convers Manage 2012;64(12):238-44.

[10] Perfumo C, Kofman E, Braslavsky JH, Ward JK. Load management: Model-based control of aggregate power for populations of thermostatically controlled loads. Energy Convers Manage 2012;55(3):36-48.

[11] Callaway DS. Tapping the energy storage potential in electric loads to deliver load following and regulation, with application to wind energy. Energy Convers Manage 2009;50(5):1389-400.

[12] Qureshi WA, Nair NC, Farid MM. Impact of energy storage in buildings on electricity demand side management. Energy Convers Manage 2011;52(5): 2110-20.

[13] Rankin R, Rousseau PG. Demand side management in South Africa at industrial residence water heating systems using in line water heating methodology. Energy Convers Manage 2008;49(1):62-74.

[14] Lund H, Möller B, Mathiesen BV, Dyrelund A. The role of district heating in future renewable energy systems. Energy 2010;35(3):1381-90.

[15] Münster M, Morthorst PE, Larsen HV, Bregnbæk L, Werling J, Lindboe HH, et al. The role of district heating in the future Danish energy system. Energy 2012;48(12):47-55. 
[16] Wittrup S. A large amount of uncontrollable heat pumps requires more power plants. < http://ing.dk/artikel/106844-et-vaeld-af-ustyrlige-varmepumper-stiller-krav-om-flerekraftvaerker>; 2010 [accessed 22.02.13] [in Danish].

[17] Papaefthymiou G, Hasche B, Nabe C. Potential of Heat Pumps for Demand Side Management and Wind Power Integration in the German Electricity Market. IEEE Trans Sust Energy 2012;3:636-42.

[18] Hedegaard K, Mathiesen BV, Lund H, Heiselberg P. Wind power integration using individual heat pumps - Analysis of different heat storage options. Energy 2012;47:284-93. [19] Klobasa M. Analysis of demand response and wind integration in Germany's electricity market. IET Renewable Power Generation 2010;4:55-63.

[20] Energinet.dk. Efficient utilisation of wind power in Denmark. <http://www.windpower.org/download/857/Effektiv_anvendelse_af_vindkraftbaseret_el_i_Dan mark.pdf >; 2009 [accessed 08.02.13] [in Danish].

[21] Danish Energy Association, Energinet.dk. Smart grid in Denmark. $<w w w . d a n s k e n e r g i . d k>$; 2010 [accessed 08.01.13] in Danish].

[22] Energinet.dk. Potential and possibilities for flexible electricity demand with particular focus on individual heat pumps. $<$ :http://www.energinet.dk $>$; 2011 [accessed 08.01.13] [in Danish]. [23] Hedegaard K, Balyk O. Energy system investment model incorporating heat pumps with thermal storage in buildings and buffer tanks. Submitted to Energy.

[24] Ravn H, Hindsberger M, Petersen M, Schmidt R, Bøg R, Grohnheit PE. Balmorel: A model for analyses of the electricity and CHP markets in the Baltic Sea region. < http://www.balmorel.dk >; 2001 [accessed 05.11.12]. 
[25] Connolly D, Lund H, Mathiesen BV, Leahy M. A review of computer tools for analysing the integration of renewable energy into various energy systems. Appl. Energy 2010;87(4):105982.

[26] Ravn H. The Balmorel Model Structure. <http://www.balmorel.com>; 2011 [accessed 03.07.13].

[27] Braun JE. Load control using building thermal mass. J. Solar Energy Eng. 2003;125:292301.

[28] Hammer O, Danfoss, Section for heat pumps, personal communication, October, 2012. [29] Danish Energy Agency. Energy statistics 2010. <http://www.ens.dk/dadk/info/talogkort/statistik_og_noegletal/aarsstatistik/Sider/Forside.aspx>; 2011 [accessed 03.10.12] [in Danish].

[30] COWI, Danish Technological Institute, Danish Gas Technology Centre. Technology data for energy plants - Individual heating plants and energy transport. Developed for the Danish Energy Agency.< http://www.ens.dk/Documents/Netboghandel\%20\%20publikationer/2012/Technology_data_for_individual heating_plants_and\%20energy transp ort.pdf>; 2012 [accessed 05.10.12].

[31] Danish Commission on Climate Change Policy. Documentation for the report of the Danish commission on climate change policy. <http://www.ens.dk/da-dk/politik/dansk-klima-og-energipolitik/klimakommissionen/klimakommissionensrapport/sider/forside.aspx>; 2010 [accessed 15.09.12] [in Danish].

[32] Jensen KA. Dimensioning of heat pumps most important. < http://www.tekniq.dk/PresseOgNyheder/Nyheder/2010/Marts/Dimensionering-af-varmepumperer-vigtigst.aspx>; 2010 [accessed 25.09.12] [in Danish]. 
[33] Risø DTU, Ea Energy Analyses. Background note on the reference scenario U and future scenario U. < $\underline{\text { http://www.ens.dk/da-DK/Politik/Dansk-klima-og-energi- }}$ politik/klimakommissionen/klimakommissionensrapport/baggrundsrapporter/Sider/Forside.aspx >; 2010 [accessed 15.09.12] [in Danish].

[34] Wittchen KB. Potential energy savings in existing buildings. Danish Building Research Institute. $<\underline{\text { http://www.sbi.dk/miljo-og-energi/energibesparelser/potentielle-energibesparelser-i- }}$ det-eksisterende-byggeri/potentielle-energibesparelser-i-det-eksisterende-byggeri>; 2009 [accessed 14.09.12] [in Danish].

[35] Rambøll Denmark A/S, Aalborg University. Heat plan Denmark, Appendix. Danish District


[accessed 12.09.12] [in Danish].

[36] Müller B. Heat atlas for the stock of existing Danish buildings - data received in access format from the author. Aalborg University, Aalborg, Denmark; 2008.

[37] Wittchen KB. Assessment of the heat saving potential in existing buildings. Danish Building Research Institute. $<\underline{\text { http://www.sbi.dk/miljo-og- }}$ energi/energibesparelser/energibesparelser-i-eksisterende-bygninger/vurdering-af-potentialet-forvarmebesparelser-i-eksisterende-boliger>; 2004 [accessed 14.09.12] [in Danish]. [38] Christiansen CH, Danish Technological Institute, personal communication, March, 2012. [39] Mortensen K, Saint Gobain Weber, personal communication, November, 2012. [40] Bolius Knowledge center for house owners. Floor heating in older houses. <http://www.bolius.dk/alt-om/energi/artikel/gulvvarme-i-aeldre-huse/>; 2006 [accessed 07.11.12] [in Danish]. 
[41] Aggerholm S, Grau K, SBi Instruction 213 - Buildings' Energy Demands, PC Programme and Calculation Instruction, Danish Building Research Institute, Hørsholm, Denmark, 2008. [in Danish].

[42] Olsen L, Danish Technological Institute, personal communication, June 2010, November 2012.

[43] Chrisensen H, Danfoss, Floor heating department, personal communication, November, 2012.

[44] Energinet.dk. Measurements of heat pump installations in Danish households - from the project Control your heat pump. < $\underline{w w w . s t y r d i n v a r m e p u m p e . d k ~}>$; 2012 [accessed 02.03.12]. [45] Andersen JJ, Vølund Varmeteknik, personal communication, August, 2010, March, 2012. [46] Halvgaard R, Kjølstad NK, Madsen H, Jørgensen JB. Economic model predictive control for climate control of buildings in a smart energy system. In: 50th IEEE Conference on Decision and Control and European Control Conference (CDC-ECC), Orlando, USA, December, 2011. [47] Pedersen TS, Andersen P, Nielsen KM, Staermose HL, Pedersen PD. Using Heat Pump Energy Storages in the Power Grid. In: IEEE International Conference on Control Applications (CCA), Denver, CO, USA, September, 2011.

[48] Wang PR, Scharling M, Nielsen KP. 2001 - 2010 Design reference year for Denmark. Danish Meteorological Institute <http://www.dmi.dk/dmi/tr12-17.pdf >; 2012 [accessed 03.02.13] [in Danish].

[49] Hedegaard K. Wind power integration with heat pumps, heat storages, and electric vehicles - Energy systems analysis and modelling. PhD thesis. DTU Management Engineering, Technical University of Denmark, Kgs. Lyngby, Denmark, 2013. 
[50] International Energy Agency, World energy outlook 2009, International Energy Agency, Paris, France, 2009.

[51] Danish Energy Agency. Preconditions for socio-economic analyses in the field of energy. $<\underline{\text { http://www.ens.dk/da- }}$

DK/Info/TalOgKort/Fremskrivninger/beregningsforudsatninger/Sider/Forside.aspx>; 2011 [accessed 01.09.12] [in Danish].

[52] The Danish Government, Det Konservative Folkeparti, Venstre, Socialistisk Folkeparti. Aggreement on increased use of biomass in the energy supply and for industrial purposes. < http://www.ens.dk/da-dk/politik/dansk-klima-og-energipolitik/politiskeaftaler/Sider/1993og1997Biomasseaftale.aspx >; 1993 [accessed 15.10.12] [in Danish].

[53] The Danish Government. Our energy. $<$ http://www.ens.dk/DA-DK/politik/dansk-klima-ogenergi-politik/voresenergi/Sider/Forside.aspx >; 2011 [accessed 08.10.12] [in Danish].

[54] Beurskens LWM, Hekkenberg M, Vethman P. Renewable energy projections as published in the national renewable energy action plans of the European member states. ECN and European Environment Agency, Petten, The Netherlands, 2011.

[55] German Ministry of Justice. Act on the peaceful uses of nuclear energy and the protection against its hazards $\S$ approval of power plants. $<\underline{\text { http://www.gesetze-im- }}$ internet.de/atg/_7.html;>; 2011 [accessed 01.10.11] [in German].

[56] Mathiesen B, Lund H, Karlsson K. The IDA climate plan 2050 - background report. Danish Society of Engineers. http://ida.dk/sites/prod.ida.dk/files/UK-

Future\%20Climates\%20Background\%20Report.pdf; 2009 [accessed 02.02.13]. 
[57] International Energy Agency, Tackling investment challenges in power generation, International Energy Agency , Paris, France, 2007.

[58] Danish Energy Agency. Technology data for energy plants.

$<$ http://www.ens.dk/Documents/Netboghandel\%20-

\%20publikationer/2010/Technology_data_for_energy_plants.pdf >; 2010 [accessed 03.09.12].

[59] Morthorst PE. Heat pumps and low temperature district heating - reporting from two workshops. Tech. Rep. Risø-R-1234(DA), Risø DTU National Laboratory for Sustainable Energy, Roskilde, Denmark.

[60] Pedersen TE, COWI, Energy department, personal communication on experiences from the large heat pump installed in Frederikshavn in Denmark, April, 2011.

[61] Danish Energy Agency, Energinet.dk. Technology data for energy plants - generation of electricity and district heating, energy storage and carrier generation and conversion. < http://www.ens.dk/Documents/Netboghandel\%20-

\%20publikationer/2012/Teknologikatalog_2012.pdf>; 2012 [accessed 02.10.12].

[62] Danish Energy Association, Heat pumps as part of the flexible electricity demand, background note for the report: The little blue about heat pumps, Copenhagen, Denmark, 2010 [in Danish].

[63] Danfoss. Danfoss living connect, product prices. <http://www.billigvvs.dk/VarmesystemerRadiatorer-Radiator-tilbehoer-Danfoss-Living-Connect.html>; 2011 [accessed 14.11.11].

[64] Kiviluoma J, Meibom P. Methodology for modelling plug-in electric vehicles in the power system and cost estimates for a system with either smart or dumb electric vehicles. Energy 2011;36(3):1758-67. 
Table 1. Main scenarios analysed in the optimisation.

\begin{tabular}{llll}
\hline & NOiHP & iHP & iHP-Flex \\
\hline Investment in individual heat pumps allowed & + & + \\
Investment in intelligent passive/active heat & & + \\
storage in the building structure allowed & & \\
Investment in heat accumulation tanks allowed & & + \\
\hline${ }^{\mathrm{a}}$ Indoor temperature variation allowed in this regard: Day: $20-23^{\circ} \mathrm{C}$, Night: $19-22{ }^{\circ} \mathrm{C}$.
\end{tabular}


Table 2. Electricity and heat demands modelled in 2030 (TWh).

\begin{tabular}{lrrrrr}
\hline & Denmark $^{\mathrm{a}}$ & Finland & Germany & Norway & Sweden \\
\hline Electricity & 30.1 & 98.1 & 569.6 & 145.3 & 160.5 \\
District heating $^{\mathrm{b}}$ & 32.5 & 34.1 & 86.8 & 1.9 & 46.4 \\
Indiv. heating, one-family houses & 13.1 & - & - & - & - \\
\hline
\end{tabular}

${ }^{a}$ Demands of the Future scenario in [31] are used.

${ }^{\mathrm{b}}$ Incl. district heating to industry. 
Table 3. Modelled stock of existing individually heated one-family houses in Denmark by 2030.

\begin{tabular}{|c|c|c|c|c|c|c|}
\hline & \multirow[b]{2}{*}{ Unit $^{\mathrm{c}}$} & \multirow{2}{*}{$\begin{array}{c}\text { Average or } \\
\text { total }\end{array}$} & \multicolumn{3}{|c|}{ Construction period } & \multirow[b]{2}{*}{ Ref. } \\
\hline & & & $1850-1960$ & 1961-1978 & 1979-2005 & \\
\hline Av. net heat demand ${ }^{a}$ & $\mathrm{kWh} / \mathrm{m}^{2}$ & 122 & 157 & 111 & 68 & {$[31,34-36]$} \\
\hline Net heat demand & TWh & 13.1 & 7.4 & 4.1 & 1.6 & {$[31,34-36]$} \\
\hline Heated floor area & $10^{6} \mathrm{~m}^{2}$ & 108 & 47 & 37 & 24 & {$[31,34-36]$} \\
\hline House size, av. & $\mathrm{m}^{2} /$ house & 151 & 142 & 151 & 171 & {$[37]$} \\
\hline Floor heating share & $\%$ & $5 \% / 9 \%{ }^{b}$ & $0 \%$ & $0 \%$ & $40 \%$ & {$[38,39]$} \\
\hline Hot water share & pct. & $17 \%$ & $13 \%$ & $16 \%$ & $28 \%$ & [37] \\
\hline
\end{tabular}

${ }^{a}$ After heat savings based on [31] and [34], representing improvement of the building envelope. Net heat demand: demand for heating from installation considering heat losses and heat contributions.

b $5 \%$ of net heat demand and $9 \%$ of heated floor area.

${ }^{\mathrm{c}}$ All areas given in $\mathrm{m}^{2}$ refer to heated floor areas. 
Table 4. Fuel and $\mathrm{CO}_{2}$ prices assumed for 2030 (€/GJ).

\begin{tabular}{|c|c|c|c|c|}
\hline \multirow[b]{2}{*}{$€ / G J$} & \multirow[b]{2}{*}{$\begin{array}{l}\text { Main } \\
\text { scenario [31] }\end{array}$} & \multirow[b]{2}{*}{$\begin{array}{l}\text { Sensitivity } \\
\text { analysis [31] }\end{array}$} & \multicolumn{2}{|c|}{ Transport cost [51] } \\
\hline & & & $\begin{array}{l}\text { Power } \\
\text { plant }\end{array}$ & $\begin{array}{l}\text { Individual } \\
\text { consumer }\end{array}$ \\
\hline $\begin{array}{l}\text { Crude oil } \\
\text { (\$/barrel) }\end{array}$ & 120 & 94 & - & - \\
\hline Coal & 3.1 & 1.8 & 0 & - \\
\hline Natural gas & 9.3 & 7.4 & 0.4 & 3.3 \\
\hline Straw & 5.3 & 5.3 & 1.8 & - \\
\hline Wood pellets & 11.5 & 11.6 & 0 & 3.4 \\
\hline Wood chips & 6.4 & 6.4 & 1.6 & - \\
\hline Biogas & 14.1 & 14.1 & 0 & - \\
\hline Munic. waste & -3 & -3 & - & - \\
\hline $\mathrm{CO}_{2}$ (€/tonne) & 38 & 77 & - & - \\
\hline
\end{tabular}


Table 5. Danish biomass and waste potentials in 2030 [31].

\begin{tabular}{ll}
\hline Fuel & Potential (PJ) \\
\hline Straw & 40 \\
Wood chips/wood & 101 \\
waste $^{\text {a }}$ & \\
Biogas & 32 \\
Munic. waste & 43 \\
\hline
\end{tabular}

${ }^{\mathrm{a}}$ Wood residues and energy crop potential available for heat \& power generation. 
Table 6. Power \& district heating technologies assumed available for investment in 2030.

\begin{tabular}{|c|c|c|c|c|c|c|c|c|c|}
\hline Technology & Fuel & $\begin{array}{l}\text { Inv. cost } \\
(\mathrm{M} € / \mathrm{MW})^{\mathrm{a}}\end{array}$ & $\begin{array}{l}\text { Var O\&M } \\
(€ / \mathrm{MWh})\end{array}$ & $\begin{array}{l}\text { Fix O\&M } \\
(\mathrm{k} € / \mathrm{MW} / \mathrm{yr})\end{array}$ & $\begin{array}{l}\text { Lifetime } \\
\text { (years) }\end{array}$ & Eff. $^{\text {b }}$ & $\mathrm{CB}$ & $\mathrm{CV}$ & Ref. \\
\hline $\begin{array}{l}\text { Open cycle gas turbine, } \\
\text { condensing }\end{array}$ & Natural gas & 0.34 & 2.5 & 16.8 & 25 & 0.46 & - & - & {$[57,58]$} \\
\hline $\begin{array}{l}\text { Combined cycle gas } \\
\text { turbine, extraction, } \mathrm{CHP}^{\mathrm{c}}\end{array}$ & Natural gas & 0.58 & 3.4 & 21.0 & 25 & 0.61 & 1.75 & 0.13 & {$[57,58]$} \\
\hline $\begin{array}{l}\text { Steam turbine, extraction, } \\
\text { CHP }^{c}\end{array}$ & Coal & 1.47 & 7.3 & - & 40 & 0.52 & 1.01 & 0.15 & {$[58]$} \\
\hline $\begin{array}{l}\text { Steam turbine, extraction, } \\
\text { CHP }\end{array}$ & Wood pellets & 1.47 & 7.3 & - & 40 & 0.52 & 1.01 & 0.15 & [58] \\
\hline $\begin{array}{l}\text { Steam turbine, extraction, } \\
\text { CHP }\end{array}$ & Wood chips & 1.68 & 3.4 & 24.1 & 30 & 0.49 & 0.61 & 0.15 & {$[58]$} \\
\hline $\begin{array}{l}\text { Steam turbine, back } \\
\text { pressure, CHP }\end{array}$ & Straw & 2.31 & 6.4 & 39.8 & 25 & 1.02 & 0.4 & - & {$[58]$} \\
\hline $\begin{array}{l}\text { Centralised biogas plant, } \\
\text { back pressure, CHP }\end{array}$ & Biogas & 5.45 & 34.6 & - & 20 & 0.92 & 1.07 & - & {$[58]$} \\
\hline $\begin{array}{l}\text { Steam turbine, back } \\
\text { pressure, CHP }\end{array}$ & Munic. waste & 8.91 & 23.1 & 162.4 & 20 & 0.97 & 0.37 & - & {$[58]$} \\
\hline Offshore wind turbine & - & 2.31 & 15.7 & - & 25 & 1.00 & - & - & {$[58]$} \\
\hline Onshore wind turbine & - & 1.28 & 12.0 & - & 25 & 1.00 & - & - & [58] \\
\hline Photo voltaic & Sun & 1.83 & 18.9 & - & 30 & 1.00 & - & - & [58] \\
\hline Heat pump, waste-water & Electricity & 0.70 & - & 7.0 & 20 & 3.0 & - & - & {$[20,59,60]$} \\
\hline Electric boiler & Electricity & 0.08 & 0.5 & 1.0 & 20 & 0.99 & - & - & [58] \\
\hline Heat boiler & Wood chips & 0.09 & - & 3.3 & 20 & 1.01 & - & - & [58] \\
\hline Heat boiler & Natural gas & 0.52 & - & 24.6 & 20 & 1.08 & - & - & [58] \\
\hline Heat boiler & Munic.waste & 1.15 & 5.6 & 52.4 & 20 & 0.98 & - & - & [58] \\
\hline Solar thermal & Sun & 0.22 & 0.5 & - & 20 & 1.00 & - & - & [58] \\
\hline Thermal storage tanks & - & 0.0030 & - & - & 40 & 0.99 & - & - & [61] \\
\hline
\end{tabular}

${ }^{\mathrm{a}}$ Investment costs for thermal storage tanks are given in M€/MWh storage and for heat pumps in M€/MWthermal.

${ }^{\mathrm{b}}$ For heat boilers, heat efficiency, for heat pumps, coefficient of performance , and for other units, electric efficiency (for CHP extraction plants, electric efficiency in condensing operation).

${ }^{\mathrm{c}}$ Excluded for investment in Denmark in the light of the Danish political phase out of coal by 2030, and the goal of $100 \%$ renewable energy use for electricity and heat generation by 2035. 
Table 7. Individual heating technologies assumed available for investment in 2030.

\begin{tabular}{|c|c|c|c|c|c|c|c|c|}
\hline Technology & Fuel & $\begin{array}{l}\text { Inv. cost } \\
(\mathrm{M} € / \mathrm{MW})\end{array}$ & $\begin{array}{l}\text { Inv. cost } \\
(€ / \text { house })\end{array}$ & $\begin{array}{l}\text { Fix O\&M } \\
(\mathrm{k} € / \mathrm{MW} / \mathrm{yr})\end{array}$ & $\begin{array}{l}\text { Var O\&M } \\
\text { (€/MWh) }\end{array}$ & $\begin{array}{l}\text { Lifetime } \\
\text { (years) }\end{array}$ & Eff.c & Ref. \\
\hline Heat pump, air/water & Electricity & 0.78 & - & 5.1 & - & 15 & 3.1 & {$[14,30]$} \\
\hline Heat pump, ground ${ }^{\mathrm{b}}$ & Electricity & 1.56 & - & 5.1 & - & $15 / 40$ & 3.8 & {$[14,30]$} \\
\hline Natural gas boiler & Natural gas & 0.50 & - & 4.0 & 7.2 & 22 & 1.02 & {$[30]$} \\
\hline $\begin{array}{l}\text { Biomass boiler, automatic } \\
\text { stoking }\end{array}$ & Wood pellets & 0.98 & - & 3.0 & - & 20 & 0.91 & {$[14,30]$} \\
\hline Solar thermal & Sun & 1.10 & - & 14.8 & 0 & 30 & 1.00 & {$[30]$} \\
\hline $\begin{array}{l}\text { Heat accum. tank, space heating } \\
\left(1000 \text { litres }^{\mathrm{a}}\right.\end{array}$ & - & 0.073 & 1275 & - & - & 40 & 0.99 & {$[62]$} \\
\hline Digital thermostats (wireless) & - & - & 312 & - & - & 15 & & {$[63]$} \\
\hline Central controller & - & - & 134 & - & - & 15 & - & {$[62]$} \\
\hline
\end{tabular}

${ }^{a}$ Investment costs for heat storages are given as M€/MWh storage capacity.

b Data in [14] for today's heat pumps in radiator systems (after heat savings) are projected to 2030 based on [30]. Costs include an electric boiler supplementing in covering peak loads. For ground source heat pumps, a life time of 15 years for the heat pump unit and 40 years for pipes in the ground [14].

${ }^{\mathrm{c}}$ For heat boilers, heat efficiency, for heat pumps, annual COP including electric boiler, and for heat storages, accounting for $1 \%$ heat loss per hour. For simplicity and due to the low share of floor heating, same COP for floor heating as for radiator heating is applied. 

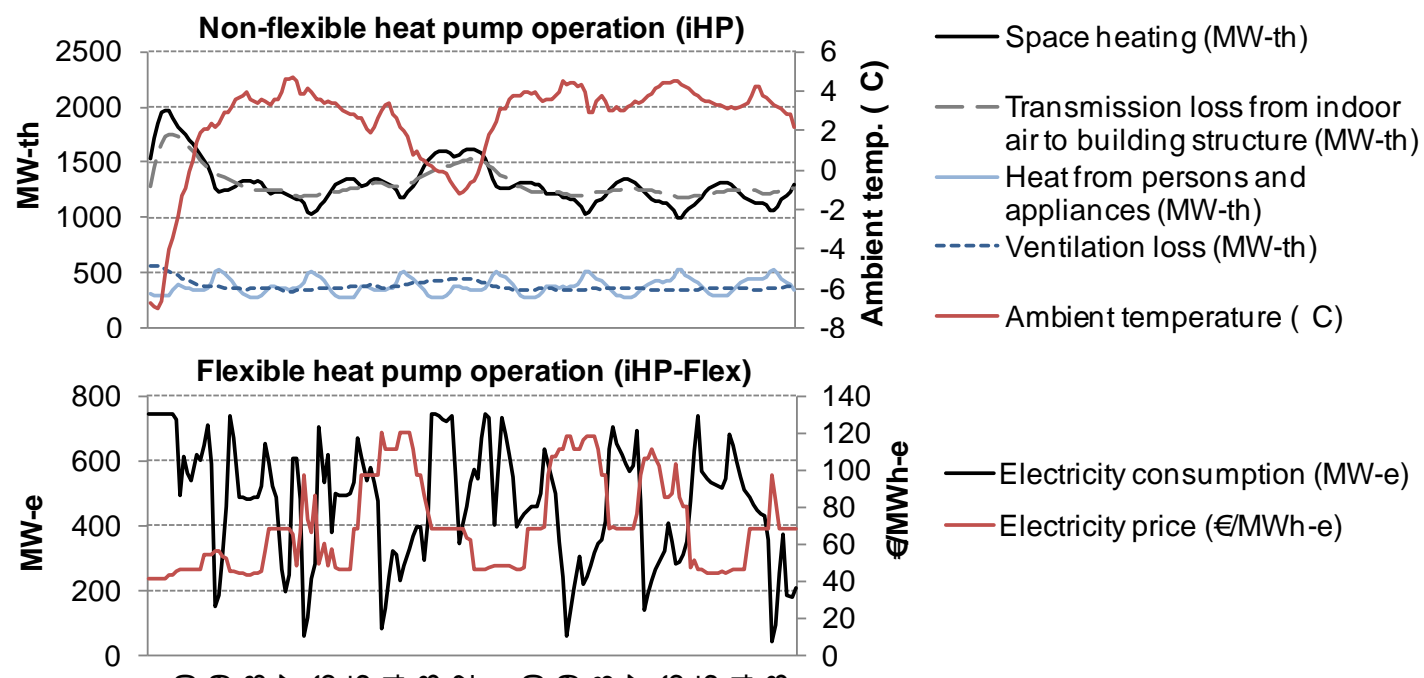

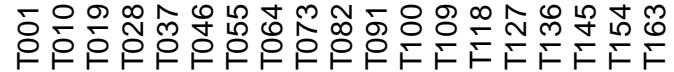

Hour

Fig. 1 


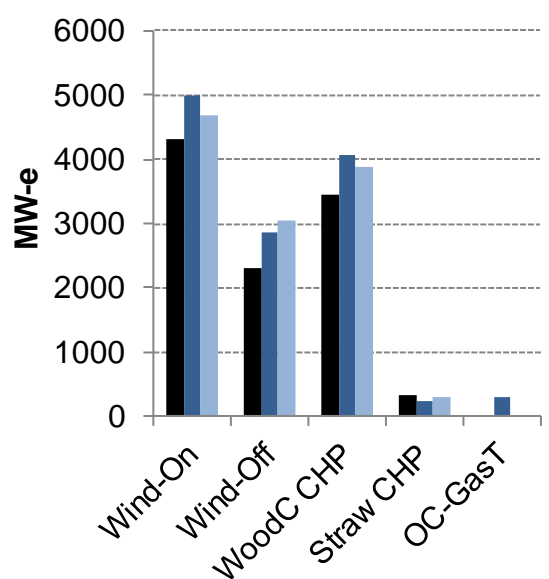

Fig. 2 a)

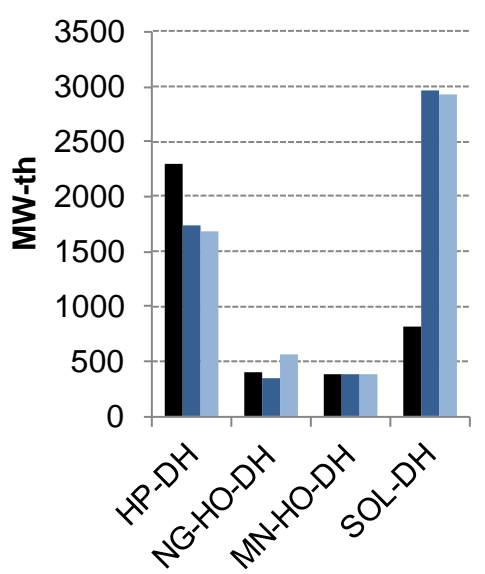

b)

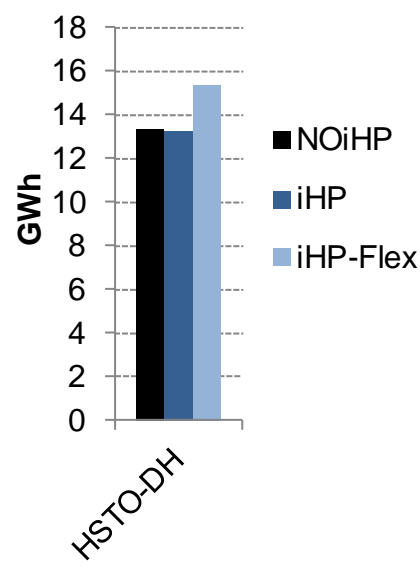

c) 


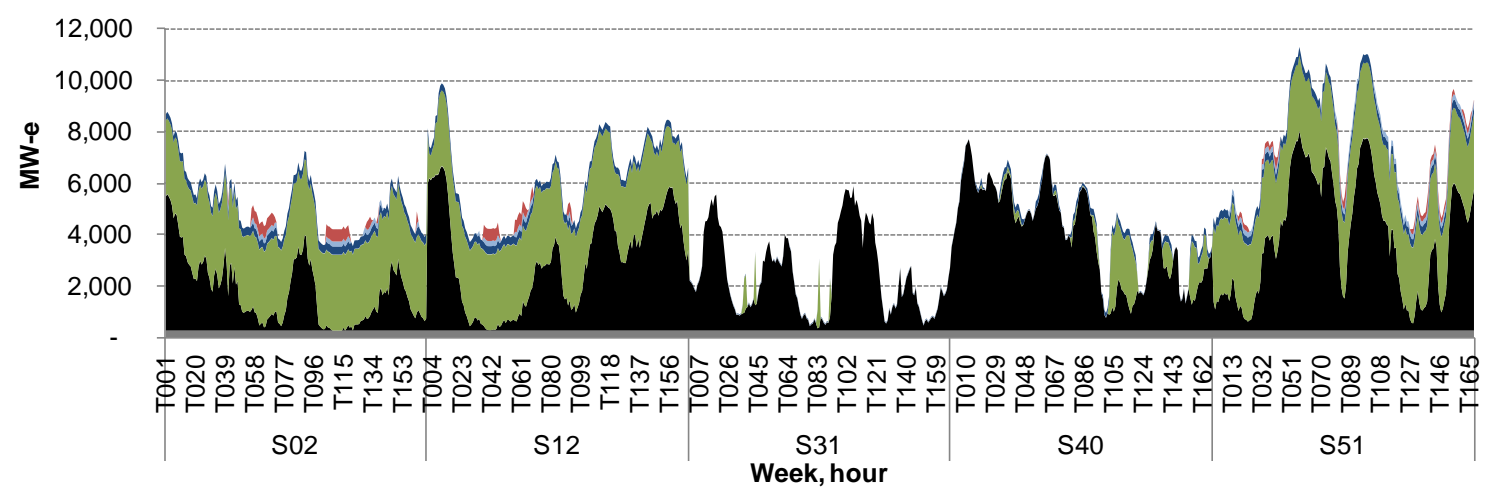

Natural gas

Wood pellets

- Straw

Wood chips

- Wind

Munic. waste

Fig. 3 


$$
\|_{1.1 .1}=
$$




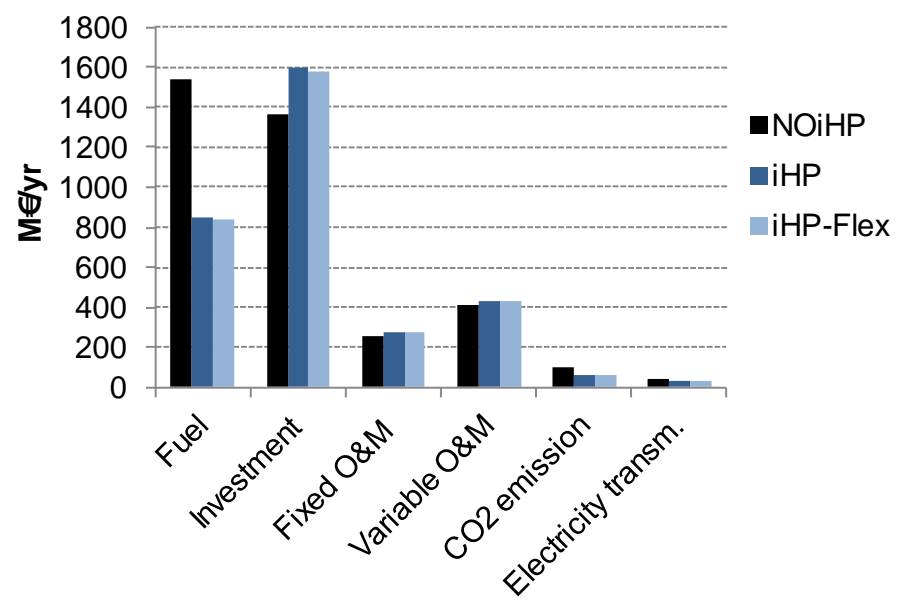

Fig. 5 


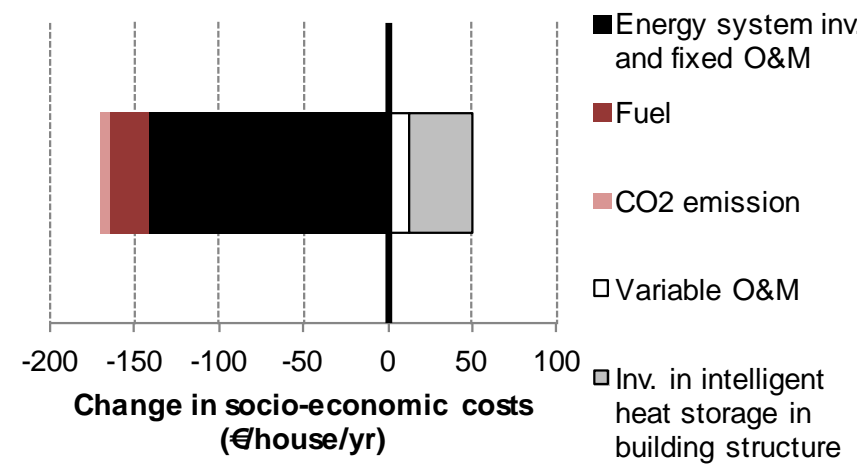

Fig. 6 